\title{
Peripheral and central mechanisms involved in the control of food intake by dietary amino acids and proteins
}

\author{
Gilles Fromentin ${ }^{1,2 *}$, Nicolas Darcel ${ }^{2,3}$, Catherine Chaumontet ${ }^{1,2}$, Agnes Marsset-Baglieri ${ }^{1,2}$, \\ Nachiket Nadkarni ${ }^{3}$ and Daniel Tomé ${ }^{1,2}$ \\ ${ }^{1}$ INRA, CNRH-IdF, UMR914 Nutrition Physiology and Ingestive Behaviour, F-75005 Paris, France \\ ${ }^{2}$ AgroParisTech, CNRH-IdF, UMR914 Nutrition Physiology and Ingestive Behaviour, F-75005 Paris, France \\ ${ }^{3}$ Chaire ANCA, F-75005 Paris, France
}

\section{Abstract}

The present review summarises current knowledge and recent findings on the modulation of appetite by dietary protein, via both peripheral and central mechanisms. Of the three macronutrients, proteins are recognised as the strongest inhibitor of food intake. The well-recognised poor palatability of proteins is not the principal mechanism explaining the decrease in high-protein (HP) diet intake. Consumption of a HP diet does not induce conditioned food aversion, but rather experience-enhanced satiety. Amino acid consumption is detected by multiple and redundant mechanisms originating from visceral (during digestion) and metabolic (inter-prandial period) sources, recorded both directly and indirectly (mainly vagus-mediated) by the central nervous system (CNS). Peripherally, the satiating effect of dietary proteins appears to be mediated by anorexigenic gut peptides, principally cholecystokinin, glucagon-like peptide- 1 and peptide YY. In the CNS, HP diets trigger the activation of noradrenergic and adrenergic neurons in the nucleus of the solitary tract and melanocortin neurons in the arcuate nucleus. Additionally, there is evidence that circulating leucine levels may modulate food intake. Leucine is associated with neural mechanisms involving mammalian target of rapamycin (mTOR) and AMP-activated protein kinase (AMPK), energy sensors active in the control of energy intake, at least in the arcuate nucleus of the hypothalamus. In addition, $\mathrm{HP}$ diets inhibit the activation of opioid and GABAergic neurons in the nucleus accumbens, and thus inhibit food intake by reducing the hedonic response to food, presumably because of their low palatability. Future studies should concentrate on studying the adaptation of different neural circuits following the ingestion of protein diets.

Key words: Proteins: Amino acids: Satiety: Gut-brain axis: Central nervous system

\section{Introduction}

The macronutrient composition of a diet is well known to influence energy intake, energy metabolism and long-term changes to body weight and body composition. Highprotein (HP) diets have been extensively studied for their ability to reduce total energy intake and body weight, and to limit fat deposition ${ }^{(1)}$. Among the three macronutrients, protein has been shown to have the greatest satiating effect $^{(2)}$. Indeed, dietary proteins are potent inducers of satiety and inhibitors of food intake in both rats ${ }^{(3)}$ and $\operatorname{man}^{(4,5)}$.

Appetite or hunger is the internal driving force for search, choice and ingestion of food in order to maintain energy homeostasis and body weight, and is therefore responsible for meal initiation. Appetite is antagonised by both satiation (defined as the physiological process that leads to meal termination) and satiety (defined as the period after a meal before the onset of hunger).

Numerous partially redundant hypotheses have been proposed to explain the effects of dietary protein and amino acids on food intake decrease ${ }^{(4-6)}$. All proposed theories mostly differ on the putative location at which the reduction in eating signals is initiated. After nutrient ingestion, pre-absorptive signals originating from the intestine are transmitted to the brain's satiety centres, via the action of gut peptides on peripheral nerves or via the bloodstream. Post-absorptive signals, occurring after nutrients and/or gut peptides cross the gut wall and enter circulation, are initiated in the hepatic-portal zone. Finally, signals relative to the status of energy stores (leptin and insulin levels)

\footnotetext{
Abbreviations: AgRP, Agouti-related peptide; AMPK, AMP-activated protein kinase; ARC, arcuate nucleus of the hypothalamus; CCK, cholecystokinin; GLP-1, glucagon-like peptide-1; HP, high protein; mTOR, mammalian target of rapamycin; NP, normal protein; NPY, neuropeptide Y; NTS, nucleus of the solitary tract; POMC, pro-opiomelanocortin; PYY, peptide YY.
} 
should also be considered as potent mediators for the effect of protein on ingestive behaviour ${ }^{(7)}$.

Furthermore, the brain areas and neuronal populations responsible for integrating these sensory signals are not yet fully understood. All these latter signals are integrated in the central nervous system where structures in the reward system, the hypothalamus and brainstem are important for the regulation of energy homeostasis as well as the onset of appetite and satiety ${ }^{(8)}$. The negativefeedback control of meal size transmitted by gastrointestinal signals and the bloodstream takes place in the dorsal vagal complex in the brainstem, and in the hypothalamic nuclei. Recently, evidence has been accumulating for a modulation of the reward system with the main consequence being the reduction of food wanting. This component of reward is known to be a major driver for eating behaviour.

The purpose of the present review is to assemble current views and knowledge concerning the neuronal mechanisms associated with peripheral and central signalling processes through which dietary protein and amino acids influence the control of energy intake.

\section{Effect of protein and amino acid intake on overall energy intake, body weight and body composition}

\section{Protein snacks (or loads)}

In the short term dietary protein appears to be a strong appetite inhibitor and reduces food intake in subsequent meals beyond that which can be accounted for by its energy content alone, both in rats ${ }^{(3,9)}$ and in $\operatorname{man}^{(10)}$. Moreover in man ${ }^{(11)}$ and in rats ${ }^{(12)}$, consumption of a HP snack delayed the request for the following meal (inter-meal interval).

In rats ${ }^{(3)}$ and $\operatorname{man}^{(10)}$, protein is currently believed to present the greatest appetite-suppressing effect of the three macronutrients. In these human studies ingestion of a HP load induces a difference in the decrease in the total meal or daily food intake in comparison with carbohydrate $e^{(13)}$ or lipid loads ${ }^{(10)}$ or both ${ }^{(2,4)}$. However, the commonly acknowledged hierarchy proteins $>$ carbohydrates $>$ lipids with respect to satiety is not always observed in rats ${ }^{(14)}$, or in human subjects ${ }^{(15,16)}$.

Many of these discrepancies have been shown to originate from the physiological status of the subjects, the duration of eating and the method of nutrient administration (meaning oral, intra-gastric or intravenous) and the nature of the $\operatorname{load}^{(17)}$. Nowadays, special attention must be given to the characteristics of the protein load: structure, texture, volume, energy density and palatability can influence the satiation or satiety induced by it. We must also take care in the selection of the subjects according to their physiological status and function (such as BMI) in conjunction with their cognitive restraint and disinhibition scores.

It has been claimed that beverages elicit weaker appetitive and/or dietary responses than solid foods ${ }^{(18)}$. Leidy has suggested that differences in satiety and food intake between protein and other macronutrients are only observed when protein is consumed as a solid and not liquid. Leidy et $a l .{ }^{(19)}$ showed that a protein-rich beverage consumed as a breakfast meal leads to weaker appetitive and dietary responses $v$, a protein-rich solid breakfast meal in adolescents. Martens et al. ${ }^{(20)}$ also investigated the differences in appetite profile and physiological parameters after consumption of a single-macronutrient, subject-specific, HP meal in liquefied $v$. solid form, controlled for energy density, weight and volume in ten lean male subjects. They observed a stronger suppression of hunger and desire to eat with the solid protein than liquefied protein. However, the hypothesis that energy consumed from solid-protein foods evokes a greater satiety response and suppresses energy intake at a subsequent meal compared with liquid foods is still unresolved. The studies of Akhavan et al. $^{(21)}$ tested the hypothesis that liquid energy is less satiating than solid energy by using pure macronutrients and similar tastes, ingredients, volumes and matrices to eliminate the confounding factors of taste, texture, smell, structure and familiarity of foods. Akhavan et $a l .{ }^{(21)}$ showed that macronutrient composition is more important than the physical state of foods in determining subjective appetite. In respect to this question, in a previous human study ${ }^{(22)}$ we compared the effect on satiety of different liquid preloads consisting only of protein, fat or carbohydrate in very controlled conditions; the preloads had the same volume, energy content, energy density, viscosity and palatability, since it had been shown that all these properties of food can affect food intake. Our results did not confirm the highest satiety effect of proteins, maybe because we used liquid, novel and unusual foods as preloads.

As with all foods, consumption of those containing proteins will generate valuable oro-sensory information due to their organoleptic properties; the latter are probably influenced by the presence of proteins in the food but are not specific. Indeed, mixtures containing proteins will have different final food textures when conditions of food processing (conditions of heating, for instance) are modified. Oro-sensory properties of foods containing proteins will be used by animals and man in learning processes such as conditioned food satiety ${ }^{(23)}$. These learning processes are likely to be involved in the satiety effect of dietary proteins. After several times of eating foods containing proteins, the subject will learn to associate the food orosensory properties with the pre- and post-ingestive effects of eating such a food. This has been shown in rats by Bensaid et al. ${ }^{(3)}$. It was shown that $2 \mathrm{~d}$ were necessary before a significant decrease was seen in the energy intake of the next protein meal, which means that as soon as the second load day, rats have learned to associate the sensory properties of the protein load with its post-ingestive consequences. In contrast, in human subjects only a few studies have shown that repeated consumption of the same food 
over a few days constitutes a learning phase for the effects on appetite of this food, which then determines food intake during the post-training test ${ }^{(24-26)}$. In all the articles the effect of repeated consumption on short-term food intake was studied using loads varying in energy density. However, the effect of protein was not determined.

Finally, protein type can affect satiety in rats (for instance, yeast proteins) ${ }^{(27)}$ and in human subjects (whey or soya protein $v$. albumin) ${ }^{(28)}$. According to Veldhorst et $a l .{ }^{(29)}$, the protein type effect could be more efficient when the protein level in the diet is not too high: differences in appetite ratings between types of protein appear when certain amino acids are above or below particular threshold values (10 and $25 \%$ of the protein:energy ratio, respectively). However, the effect of the nature of the proteins was not present in all experiments. Indeed, various proteins have been used in other experiments described in the literature, and it is still not clear if the nature of the protein can significantly affect the feeding response studied (egg albumin, casein, soya or whey or pea proteins in human subjects $)^{(30,31)}$. The results observed with biochemically very different proteins strongly suggest that the satiating effect of protein is primarily a very general property that does not depend on such specific characteristics of one or another protein ${ }^{(3)}$. Nevertheless, if protein type can influence the satiating effect, the mechanisms involved remain unclear. For instance, it could be related to a slowdown of the gastric emptying, an increase in brain amino acids, the presence of specific peptides or the presence of certain specific amino acids (see below). However, in such studies the dietary protein used to formulate the food has to be well equilibrated in its essential amino acid composition. Otherwise, eating a protein- or amino acid-imbalanced diet induces a depression in food intake induced by a conditioned food aversion ${ }^{(32,33)}$.

\section{Protein diets}

The consumption of a HP diet quickly induces a strong and immediate depression in food intake followed by a progressive but not complete return to the level of energy intake of the control diet in animals ${ }^{(1)}$. Harper \& Peters studied this phenomenon in rats by using diets whose protein content ranged from 5 to $75 \%{ }^{(34)}$. The reduction of food intake occurred when the protein content of the diet was greater than $40 \%$ (as protein:energy ratio) and was even more pronounced as it rose higher.

Taking into consideration the depression in food intake and the induced active avoidance, it has been claimed that eating a HP diet probably induces a conditioned food aver$\operatorname{sion}^{(35)}$. The respective roles of conditioned food aversion, satiety and palatability in the depression of food intake induced by a HP diet were studied by analysing the behavioural responses in comparison with a normal-protein (NP) $\operatorname{diet}^{(36-39)}$. Conditioned food aversion is an acquired mechanism allowing a subject to avoid consuming a food when the post-ingestive consequences are remembered as harmful. Conditioned food aversion requires that the subject links one or more oro-sensory characteristics of the food to unpleasant post-ingestive consequences. Our own experiments ${ }^{(36,37)}$ showed that only behavioural and food intake parameters were disturbed during day 1 when an animal ate the HP diet, and that most parameters returned to baseline values as soon as day 2 of the HP diet. Rats adapted to the HP diet did not acquire a conditioned food aversion but exhibited satiety, and a normal behavioural satiety sequence. Similar to ours, other studies ${ }^{(38,39)}$ did not confirm a conditioned food aversion hypothesis.

Also, it has been shown that different protein sources may differently affect food intake in a context of HP diets in rats ${ }^{(40)}$. Whatever the protein type used in the HP diet, these diets decrease average energy intake more than the NP diets. This effect is modulated by the ratio between carbohydrate and fat and by the protein type (total milk protein, whey protein or $\beta$-lactoglobulin) ${ }^{(40)}$. For example, whey-derived protein sources, and particularly $\beta$-lactoglobulin, reduce food intake, body-weight gain and the adiposity index more than total milk protein. However, we also observed that biochemically very different proteins such as total milk and soya protein induced no differences in depression of energy intake ${ }^{(41)}$. As in the case of protein snacks, this result suggests that the satiating effect of protein used in a HP diet is primarily a very general property that does not depend on specific characteristics of one or another protein, which in contrast could explain the modulation of food intake observed when different types of proteins are used.

It has been suggested that the sensing of protein ingestion by animals might be linked to the L-glutamate (free + protein bound) content in foods ${ }^{(42)}$. This might provide a reasonable index of protein ingestion because L-glutamate is the most abundant amino acid in almost all dietary proteins. Nevertheless, $15 \mathrm{~d}$ of eating a NP diet (total milk protein, protein:energy of $14 \%$ ) enriched or not in glutamate $(2 \%)$ did not induce a decrease in food intake or in weight gain ${ }^{(43)}$. Glutamic acid is well tolerated by the rat in amounts as high as 5\%, and probably up to $10 \%$, in diets with low to moderate protein content ${ }^{(44)}$

The poor palatability of HP diets has been documented ${ }^{(45)}$, but with respect to protein intake its relative importance remains unclear. It is possible that the appetite-suppressing effect of dietary protein is partially induced by poor palatability. In order to study the role of oro-sensorial factors, food intake was measured after modifying the composition of the HP diet, meaning the type of proteins or carbohydrates present ${ }^{(46)}$. However, we were unable to modify the depression of food intake induced by a HP diet. Taken together, our experiments indicate that the overall behavioural response more probably originated from an initial lower palatability of the food combined with an enhanced satiety effect of the HP diet and a delay required for the metabolic adaptation. 
Even if several studies, conducted in human subjects fed low-energy diets, have shown that using one or two HP meal replacements per $d$ might lead to a decrease in energy intake and body weight ${ }^{(47,48)}$, the long-term consequences of the consumption of protein meals in non-restricted subjects remain unknown.

The usefulness of protein diets may be questioned in relation to weight loss and maintenance of lean body mass in two different situations: that of energy restriction and that of ad libitum feeding. The effect of diet composition on weight loss during energy restriction has been widely studied and the additional effect of macronutrient composition above energy restriction was not clearly demonstrated. The absence of any effect of diet composition in human subjects (apart from energy restriction), such as the protein:carbohydrate ratio, has been reported by several authors ${ }^{(49,50)}$, although not all ${ }^{(51,52)}$. The loss of lean body mass accompanying energy restriction is a major obstacle to successful long-term dieting. One important suggestion relative to increasing dietary protein during energy restriction is that it might prevent a loss of lean body mass ${ }^{(53)}$. In rats, eating a HP diet ad libitum mainly induced a reduction in the fat mass of rats but also a higher ratio of lean:fat mass ${ }^{(1)}$. In human subjects only a few studies have been carried out in order to analyse the long-term effects on body-weight gain and adiposity of eating a diet rich in protein ad libitum. Using two isoenergetic diets in overweight subjects, Weigle et al. ${ }^{(54)}$ showed that an increase in dietary protein from 15 to $30 \%$ of energy at a constant carbohydrate intake resulted in rapid losses of weight and body fat due to a sustained decrease in appetite and energy intake.

\section{Peripheral control of amino acids and protein intake}

During digestion, proteins produce several pre- and postabsorptive signals that play a role in the control of food intake (Fig. 1).

\section{Detection of protein and amino acids during digestion and control of food intake by feedback signals}

Amino acid detection occurs as early as within the oral cavity. Indeed, several amino acids taste sweet, bitter or umami to man and are attractive to rodents and other animals $^{(55)}$. Taste receptors (namely T1R1 and T1R3 heterodimers) are present on the tongue and detect most of the twenty amino acids. Some, such as glutamate, can be detected specifically through the means of metabotropic glutamate receptors (mGluR1 and mGluR4), while others, such as glycine, taste sweet to man. There are different sources of L-glutamate in food: either protein-bound or in free form. When glutamate is protein-bound, it is tasteless and does not provide an umami taste to food. L-Glutamate is present as a free amino acid in various food products such as seaweed, soya sauce, fermented beans, an extract made from beef meat, aged cheeses, cured ham and tomatoes. Thus, it is unlikely that free glutamate is a major taste marker of dietary protein to the individual ${ }^{(42,55)}$.

Satiation feedback signals originating from the stomach are the result of volumetric signals produced by mechanoreceptors ${ }^{(56)}$. The initial increase in gastric volume subsequent to the ingestion of dietary protein is probably due to increased gastric secretions and increased water intake ${ }^{(46)}$. As explained below, dietary proteins and amino acids are detected within the duodenum and this detection delays gastric emptying ${ }^{(57)}$, hence prolonging gastric distension satiation signals. As proposed by Janssen et $a l .{ }^{(58)}$, gastric emptying is a key mediator of hunger satiation and satiety. Thus, signals originating from the stomach are likely to contribute to satiation signalling provoked by protein intake.

A strong contributor to the effect of protein and amino acids on food intake is the upper intestine. There is evidence that protein and protein digestion products, such as amino acids and oligopeptides, are detected within the lumen of the duodenum. While a first proposed mechanism for this detection is linked to protein and amino acid absorption and processing by enterocytes ${ }^{(59)}$, other groups have shown that nutrient-specific receptors exist on the apical side of enterocyte and enteroendocrine cells, being similar to either lingual taste receptors ${ }^{(60)}$ or functional oligopeptide transporters ${ }^{(61,62)}$. Ultimately, amino acid and oligopeptide detection in the intestinal wall is dependent upon the release of cholecystokinin (CCK) by enteroendocrine cells ${ }^{(63)}$. Duodenal CCK then increases the firing rate of vagus nerve afferents that extend terminals to the close vicinity of the brush border, and that convey information to the nucleus of the solitary tract (NTS) in the brainstem. The implication of this detection on food intake seems to be restricted to short-term food intake control ${ }^{(64)}$.

Within the lower intestine, the ileal brake is a feedback mechanism that results in the inhibition of proximal gastrointestinal motility and secretion. Animal and human studies have shown that activation of it by local nutrient perfusions increases feelings of satiety and reduces ad libitum food intake $^{(65)}$. These results point to a potential role for the ileal brake in the regulation of digestion, exerting a direct or indirect impact on eating behaviour and satiety. Ileal protein infusions in both human subjects and animals activate the ileal brake ${ }^{(66)}$. It is notably mediated by peptide YY (PYY), which is released by $\mathrm{L}$ cells located in the mucosa of the ileum. According to Moran \& Dailey ${ }^{(67)}$, the pattern of secretion in plasma can remain elevated for up to $6 \mathrm{~h}$ following meal termination. This long-lasting pattern of release suggests roles for this mediator that extend beyond the meal that originally stimulated its release. According to Batterham et al. ${ }^{(68)}$, a HP diet intake induced the greatest release of PYY and the most pronounced satiety in normal-weight and obese human subjects. A long-term augmentation of dietary protein in 


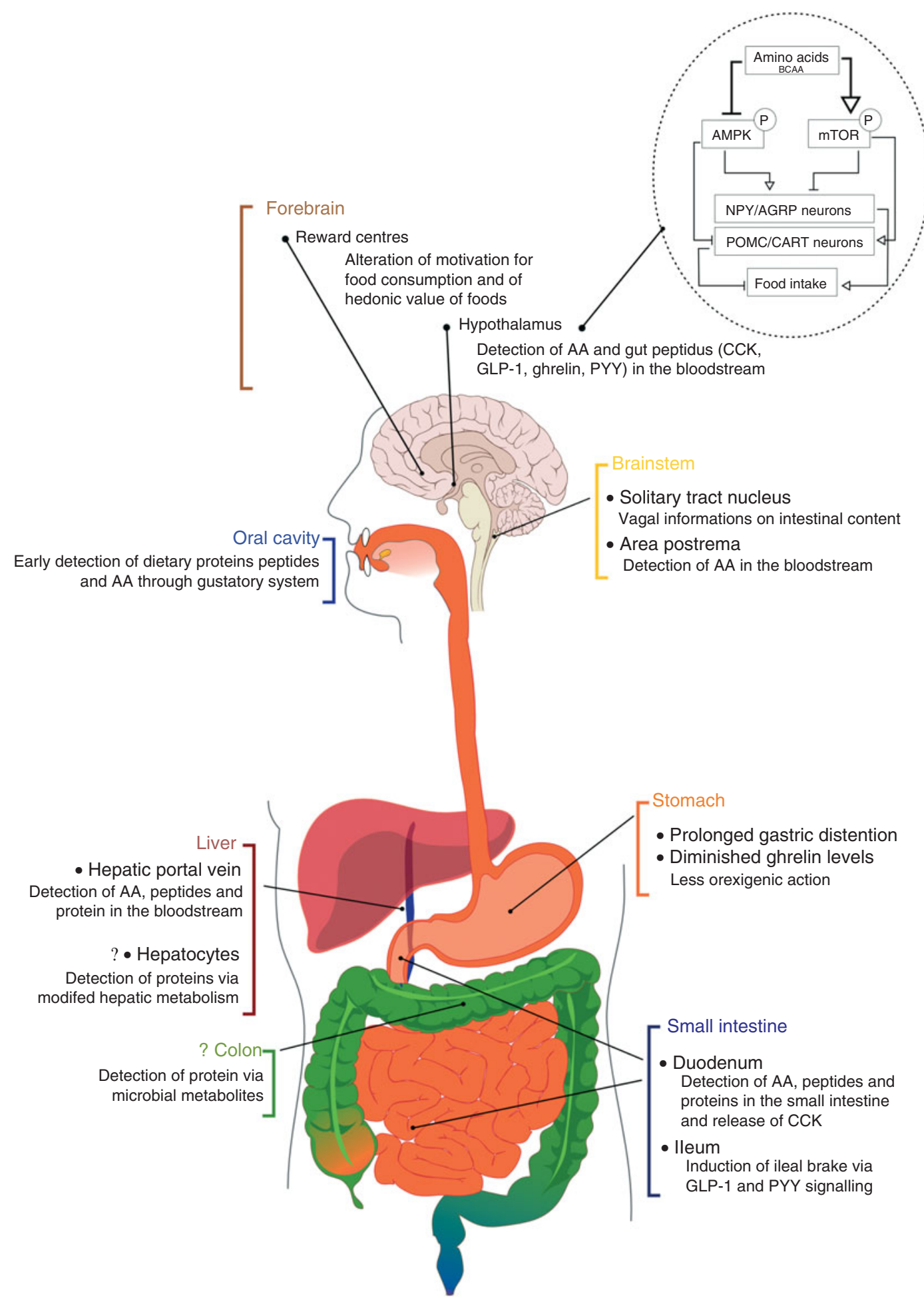

Fig. 1. Mechanisms responsible for the protein-induced suppression of food intake. BCAA, branched-chain amino acids; AMPK, AMP-activated protein kinase; mTOR, mammalian target of rapamycin; NPY, neuropeptide Y; AgRP, Agouti-related peptide; POMC, pro-opiomelanocortin; CART, cocaine and amphetamineregulated transcript; AA, amino acids; CCK, cholecystokinin; GLP-1, glucagon-like peptide-1; PYY, peptide YY.

mice induced elevated plasma PYY levels, and reduced food intake and adiposity. In order to determine directly the role of PYY in mediating the satiating effects of protein, Batterham et al. ${ }^{(68)}$ generated PYY-null mice that were selectively resistant to the satiating and weight-reducing effects of protein; these animals developed marked obesity that was reversed by exogenous PYY treatment.

In addition to CCK and PYY, a wide range of intestinal mediators have been described to be linked to dietary protein intake, as reviewed by Karhunen et al. ${ }^{(69)}$. Ghrelin, 
an orexigenic peptide, is decreased after consumption of a HP breakfast in lean subjects ${ }^{(70)}$. This result was confirmed by Bowen et al. ${ }^{(71)}$ in lean and overweight subjects but not by Westerterp's studies (reviewed in Veldhorst et al. ${ }^{(72)}$ ). It is also possible that HP diet but not HP meal intake influences ghrelin responses ${ }^{(73)}$. Also, compared with other macronutrients, dietary protein is also a very strong stimulus for gastric inhibitory polypeptide ${ }^{(74)}$ and glucagon-like peptide-1 (GLP-1) release by the small intestine ${ }^{(71)}$. Since GLP-1 receptors are expressed in vagal afferent neurons it is likely that GLP-1 acts on vagal afferent terminals in close vicinity to the enteroendocrine $\mathrm{L}$ cells ${ }^{(67)}$. Complex cooperative interplay might occur between ghrelin and CCK as described by de Lartigue et $a l .{ }^{(75)}$, and also between CCK, gastric inhibitory polypeptide and GLP-1, suggesting critical synergistic effects ${ }^{(76)}$.

The participation of hepatic portal vein vagal afferents in protein sensing and signalling to the brain is notably supported by electrophysiological recordings showing that hepatic portal vein perfusion of amino acids activates vagal afferent fibres ${ }^{(62)}$. However, hepatic vagal afferents do not seem essential to the peripheral detection of a HP diet $^{(6)}$. Others have proposed the hepatic portal vein as being the critical and necessary site for HP diets to alter food intake ${ }^{(77)}$, but this view seems rather unlikely considering the high level of redundancy present in gut-brain axis satiety signalling ${ }^{(78)}$.

Such generated signals (gut peptides but also circulating amino acids) have a dual mode of action on the central nervous system: (i) at the gastrointestinal tract via the vagus nerve to the brainstem within the NTS (the first central relay for afferent vagal fibres); and (ii) directly at the hypothalamus (arcuate nucleus of the hypothalamus; ARC) and brainstem via the bloodstream (notably through hormones and circulating nutrients acting as mediators) and an indirect transmission through the nervous system which innervates the gastrointestinal tract, namely the vagus nerve and splanchnic nerves (though sub-diaphragmatic vagotomy fails to suppress the depression of food intake induced by the administration of a HP diet in rats $\left.{ }^{(79)}\right)$.

\section{Detection of protein and amino acids, post-absorptive signals and feedback signals controlling food intake}

Since the 2000s, many studies in human subjects have been conducted to examine differences in postprandial hormone profiles that could be the cause of satiety induced by proteins. Studies have focused on CCK, GLP-1, amylin, ghrelin, leptin, insulin and glucagon, but very often no clear correlation emerged between these hormones and satiety ${ }^{(71,72)}$. As for individual mediators, studies have shown that ghrelin is primarily blood-borne and alters hypothalamic function, whereas the mode of action of CCK and GLP-1 is, in contrast, primarily vagally mediated $^{(67)}$. Plasma CCK levels are unlikely to be a relevant signal $^{(80)}$.
It must be mentioned that an increase in energy expenditure could also be the cause of peripheral signals of satiety induced by proteins. The role of dietary protein in bodyweight control could be a direct consequence of thermogenesis. Proteins are thought to produce a greater thermogenic effect than other macronutrients participating in proteininduced satiety. This is due in part to the energetic cost necessary to incorporate each amino acid into protein and for catabolism of the amino acid in excess. In human subjects $^{(4,5)}$ but not in rats ${ }^{(81)}$, ingestion of proteins stimulates postprandial thermogenesis at a higher level than other macronutrients. Conversely, it has never been shown that an increase in postprandial thermogenesis was the direct cause of satiety induced by the ingestion of food proteins. At most, correlations between dietary protein intakes, an effect on satiety and increased thermogenesis were highlighted. Furthermore, central mechanisms linking the direct effect of increased thermogenesis and postprandial satiety remain to be demonstrated.

Amino acid-induced gluconeogenesis could also prevent a decrease in glycaemia that could contribute to satiety ${ }^{(82)}$. The fact that gluconeogenesis in man is thought to remain relatively stable in varying metabolic conditions is still a matter of debate ${ }^{(83)}$. However, Velhorst et al. ${ }^{(84)}$ has shown that after a HP diet, gluconeogenesis was increased and appetite was lower compared with a NP diet; however, these were unrelated to each other. The glucostatic theory indicates that a drop of plasma glucose level precedes the start of the following meal. However, no one has shown that the flow of plasma glucose induced by the ingestion of a meal rich in protein lasts longer than one that follows a NP meal ${ }^{(15)}$.

The high plasma concentration of amino acids after the ingestion of a protein diet could be the cause of peripheral signals that would be detected in some specific regions in the hypothalamus ${ }^{(85)}$. Hall et al. ${ }^{(74)}$ explained that their results on the satiating effect of whey protein being greater than that of casein were in agreement with the work of Boirie et $a l .{ }^{(86)}$, originally the conceiver of 'slow and fast proteins', and the aminostatic theory ${ }^{(87)}$. These authors concluded that the massive influx of amino acids following ingestion of whey proteins could lead to higher satiating power of these proteins as compared with other, slower, sources of amino acids (such as casein). Finally, the presence of some specific amino acids such as glutamate or leucine could also play a role in the central control of appetite (see below).

The general hypothesis that the specific role of certain amino acid precursors of neurotransmitters would explain the decrease in food intake induced by proteins is still a matter of debate. In particular, the amount of tryptophan (the precursor of serotonin and a mediator known to inhibit appetite ${ }^{(88)}$ ) was used to demonstrate this phenomenon. The high tryptophan content of $\alpha$-lactalbumin has been suggested to explain the satiating effect of this protein $^{(29,89)}$. Indeed, the ingestion of $\alpha$-lactalbumin 
increases the plasma level of tryptophan and the tryptophan:branched-chain amino acids ratio more than other proteins such as gelatin (which is devoid of tryptophan). However, the addition of free tryptophan to gelatin at the same level as that of $\alpha$-lactalbumin does not affect responses on scales of hunger ${ }^{(29)}$. Similarly, tyrosine, a precursor of dopamine, added at a $5 \%$ level in the diet of rats had no influence on the level of intake ${ }^{(90)}$. Because the ingestion of foods high in protein (and thus L-glutamate) does not lead to appreciable changes in plasma Lglutamate concentrations ${ }^{(91)}$, the body (the brain) is unlikely to monitor protein intake via meal- or diet-related variations in plasma L-glutamate. In the same way, results concerning the addition of histidine, a precursor of histamine, to the diet are conflicting. Chronic ingestion of histidine added at a $5 \%$ level in the diet of rats had no influence on the level of intake ${ }^{(90)}$. At the same time a $8 \mathrm{~d}$ ingestion of histidine added at a $1,2.5$ or $5 \%$ level in the diet of rats decreased food intake ${ }^{(92)}$, so the role of central histamine in the depression of food intake has been suggested ${ }^{(93)}$.

\section{Protein-induced reduction in eating and central neuronal pathways}

It should be mentioned that brain recognition of deficiency in indispensable amino acid diets is out of the scope of the present review ${ }^{(32,33)}$. Well-equilibrated dietary proteins induce a reduction in food intake during a subsequent meal in parallel with activation of neuronal populations in the NTS and the hypothalamus. In addition, a HP diet inhibits the activation of opioid and GABAergic neurons in the nucleus accumbens, and thus inhibits food intake by reducing the hedonic response to food, presumably because of its low palatability (Fig. 1).

The NTS is the main entry point of the vagus nerve in the central nervous system and thus receives afferent projections from most of the organs of the gastrointestinal tract $^{(94)}$. In addition, the NTS receives some cranial nerve afferents that convey, from the oro-sensory area, extensive information on food texture, taste, smell, appearance and palatability.

The involvement of vagal afferent pathways in protein sensing and signalling to the brain is supported by results showing that intraduodenal protein activates vagal afferent fibres, and HP feeding induces c-Fos expression in neurons within the $\mathrm{NTS}^{(95,96)}$. Faipoux et al. ${ }^{(97)}$ showed that a reduction in food intake after a HP load ( $v$. a NP load) resulted from activation of the noradrenergic neurons related to CCK-induced anorexia. This study also showed that neurons expressing GLP-1 were not activated, which is consistent with the fact that protein-induced reduction in eating is not associated with conditioned food aversion ${ }^{(36)}$.

The hypothalamus is the focus of much peripheral information sensing and participates in the control of body energy homeostasis and food intake. This vast area has many nuclei that are in constant interaction ${ }^{(94)}$. The hypothalamus contains a number of discrete neuronal populations or nuclei, including the $\mathrm{ARC}$, the paraventricular nucleus (PVN), the ventromedial nucleus, the dorsomedial nucleus and the lateral hypothalamic area. Energy homeostasis-regulating circuits are found within and connecting these nuclei. In the ARC, pro-opiomelanocortin (POMC) neuron activation induces a reduction in food intake. The activation of POMC neurons is also inseparable from the behaviour of another population in the ARC, neuropeptide Y (NPY)/Agouti-related peptide (AgRP) neurons, activation of which is potent in increasing food intake and inhibiting POMC neuron activation ${ }^{(98)}$.

We have shown that after the ingestion of a HP meal, the numbers of double-labelled Fos and $\alpha$-melanocytestimulating hormone (a marker of POMC neuron activation) marked cells increased, concomitantly with a reduction in the activation of non-POMC neurons ${ }^{(97)}$. This result was less pronounced when a HP diet had been served chronically $(21 \mathrm{~d})$ than in an acute setting. Moreover, because arcuate neurons mainly exhibit a POMC or NPY phenotype, it could be hypothesised that NPY neurons are less strongly activated after HP meals. Similarly, rats or obese mice fed a HP diet ad libitum decreased their hypothalamic NPY mRNA levels and increased their hypothalamic mRNA POMC levels to a greater extent than those fed the NP diet $^{(39)}$. Using Sprague-Dawley rats maintained on a $\mathrm{HP}$-high-fat diet also resulted in significant increases in POMC expression over that of controls, with no effect on AgRP or NPY expression levels in the ARC, and increased dorsomedial nucleus NPY expression ${ }^{(38)}$. Surprisingly, a recent study reported that in wild mice fed a $\mathrm{HP}$ diet for $3 \mathrm{~d}$ (or more until $30 \mathrm{~d}$ ) there was a paradoxical decrease in expression of the hypothalamic POMC, and an increase in expression of the gene encoding $\operatorname{AgRP}^{(99)}$. However, they did not discuss their results with respect to those previously presented in this review.

It has been shown that AMP-activated protein kinase (AMPK) and the mammalian target of rapamycin (mTOR) are involved in the reduction in eating induced by HP diets. Here, an increase in dietary leucine ${ }^{(39)}$ or the intracerebroventricular administration of amino acids (or leucine only) ${ }^{(100,101)}$ reduces food intake and body weight. AMPK is the downstream component of a kinase cascade that acts as a sensor for cellular energy charge, being activated by an increase in the AMP:ATP ratio. Once activated, AMPK phosphorylates acetyl-CoA carboxylase (ACC) and switches on energy-producing pathways at the expense of energy-depleting processes. Ropelle et al. ${ }^{(39)}$ showed that both a HP diet and intra-cerebroventricular leucine administration suppressed AMPK and ACC phosphorylation in the rat hypothalamus, this being concomitant with a reduced AMP:ATP ratio. In parallel, there has been growing interest in mTOR, an intracellular signalling molecule sensitive to both amino acids and growth factors, which is also described as a metabolic sensor. Both a HP 
diet and the intra-cerebroventricular administration of free amino acids, or leucine only, led to mTOR activation in the hypothalamus ${ }^{(100,101)}$. Moreover, HP diets modulate AMPK and mTOR in the same specific neuronal subsets, the ARC and paraventricular nucleus of the hypothalamus. AMPK and mTOR may have overlapping and reciprocal functions ${ }^{(100,101)}$. Finally, the activation of $\mathrm{mTOR}$ and the suppression of AMPK phosphorylation activity seem to modulate hypothalamic neuropeptides: they reduce levels of orexigenic NPY and AgRP neuropeptides and increase the expression of POMC, which exerts an anorexigenic effect ${ }^{(39,101)}$.

This effect of HP diets seems to be leucine-specific, because intracerebral leucine alone exerts the same effect on food intake as a mixture of amino acids ${ }^{(39)}$. Moreover, using a HP diet or a NP diet enriched in leucine to the same level found in a HP diet (containing $50 \mathrm{~g}$ free leucine per kg diet) Ropelle et al. ${ }^{(39)}$ obtained the same results without causing a conditioned taste aversion. Nevertheless, such a comparison has some limits because a NP diet containing an amino acid in excess and a HP diet have different types of peripheral catabolism ${ }^{(44)}$.

The nucleus accumbens (NAcc) is a structure of the ventral striatum which is pivotal in the modulation of hedonic control of eating behaviour. It is divided into two parts, the core (AccCo) and shell (AccSh) ${ }^{(94)}$. It was identified early on as the primary interface between motivation and action in the brain, because of its many afferents (mostly glutamatergic) from regions involved in cognitive processes and learning, and its efferents to areas of motor control, mostly GABAergic. The AccCo is involved in the learning process and implementation of adaptive mechanical actions, while AccSh is more involved as a relay between cortical regions and other regions of the brain in behavioural aspects, in particular food ${ }^{(102)}$. As previously discussed, dietary proteins have a low palatability. Palatability has a major impact on the reward system but the expression of liking cannot alone explain the anorexigenic effect of proteins ${ }^{(36)}$. Proteins inhibit the activation of opioid and GABAergic neurons in the NAcc and thus could inhibit food intake by reducing the hedonic response to food $^{(103)}$. It is well known that neurons in the AccSh project directly to the lateral hypothalamic area ${ }^{(104)}$ and the stimulation of orexigenic lateral hypothalamic area neurons can induce robust feeding ${ }^{(105)}$. Chemical manipulation of the AccSh has been shown to elicit robust feeding and Fos expression in the hypothalamus, in particular in the ARC. Fos activation was significantly lower in POMC/ cocaine and amphetamine-regulated transcript (CART) neurons and higher in NPY neurons ${ }^{(106)}$. Recently we have shown that postprandial activation of NAcc is decreased by a HP diet given during $2 \mathrm{~d}$ or after a $15 \mathrm{~d}$ period $^{(107)}$ and could in turn inhibit NPY neurons and activate POMC/CART neurons in ARC.

\section{Conclusion}

Extensive studies of HP diets have demonstrated their ability to limit total energy intake, body weight and lipid deposition. They have become popular, probably because they increase satiety and aid in ensuring better compliance with a reduced-energy diet and/or contribute to a spontaneous reduction in energy intake ${ }^{(108)}$.

Nowadays we know that the protein and amino acid content of food is a determinant of control of food intake and the amount that will be eaten. The peripheral hormones CCK, GLP-1 and PYY have been shown to be involved in the mechanism of protein-induced satiety. Specific amino acids such as the branched-chain amino acid leucine, or other neuropeptide precursors (perhaps histidine), can contribute to the protein-induced control of food intake via central mechanisms. Several brain regions are involved in the central control of food intake, and more specifically it has been shown that proteins may affect them by acting in different parts of the brainstem or hypothalamus.

In the future we will have to study more precisely the interaction between different brain areas, and the adaptation of different neural circuits following the ingestion of protein diets. Also, when eating a HP diet, a fraction of dietary protein and endogenous protein escapes digestion in the small intestine and passes the ileo-caecal junction where it undergoes the action of bacterial proteases and the residual fraction of pancreatic proteases. Free amino acids are substrates used by the microbiota to generate metabolites of diverse structure, some of which have effects on cells. The role of dietary protein on the control of food intake via the microbiota remains unknown.

\section{Acknowledgements}

The present review was supported by funds from our laboratory. We acknowledge the contribution of all authors in the writing of the present review and G. F. and D. T. for conceiving the article.

The authors declare that they have no conflicts of interest.

\section{References}

1. Jean C, Rome S, Mathe V, et al. (2001) Metabolic evidence for adaptation to a high protein diet in rats. $J$ Nutr 131, 91-98.

2. Poppitt SD, McCormack D \& Buffenstein R (1998) Shortterm effects of macronutrient preloads on appetite and energy intake in lean women. Physiol Behav 64, 279-285.

3. Bensaid A, Tome D, Gietzen D, et al. (2002) Protein is more potent than carbohydrate for reducing appetite in rats. $P h y$ siol Behav 75, 577-582.

4. Latner JD \& Schwartz M (1999) The effects of a highcarbohydrate, high-protein or balanced lunch upon later food intake and hunger ratings. Appetite 33, 119-128. 
5. Westerterp-Plantenga MS, Nieuwenhuizen A, Tome D, et al. (2009) Dietary protein, weight loss, and weight maintenance. Annu Rev Nutr 29, 21-41.

6. Tome D, Schwarz J, Darcel N, et al. (2009) Protein, amino acids, vagus nerve signaling, and the brain. Am J Clin Nutr 90, 838S-843S.

7. Schwartz MW, Woods SC, Porte D Jr, et al. (2000) Central nervous system control of food intake. Nature 404, 661-671.

8. Berthoud HR (2011) Metabolic and hedonic drives in the neural control of appetite: who is the boss? Curr Opin Neurobiol 21, 888-896.

9. Trigazis L, Orttmann A \& Anderson GH (1997) Effect of a cholecystokinin-A receptor blocker on protein-induced food intake suppression in rats. Am $J$ Physiol 272, R1826-R1833.

10. Porrini M, Santangelo A, Crovetti R, et al. (1997) Weight, protein, fat, and timing of preloads affect food intake. Physiol Behav 62, 563-570.

11. Marmonier C, Chapelot D \& Louis-Sylvestre J (2000) Effects of macronutrient content and energy density of snacks consumed in a satiety state on the onset of the next meal. Appetite 34, 161-168.

12. Burton-Freeman B, Gietzen DW \& Schneeman BO (1997) Meal pattern analysis to investigate the satiating potential of fat, carbohydrate, and protein in rats. Am J Physiol 273, R1916-R1922.

13. Bertenshaw EJ, Lluch A \& Yeomans MR (2008) Satiating effects of protein but not carbohydrate consumed in a between-meal beverage context. Physiol Behav 93, 427-436.

14. Geliebter A, Liang JT \& Van Itallie TB (1984) Effects of repeated isocaloric macronutrient loads on daily food intake of rats. Am J Physiol 247, R387-R392.

15. Marmonier C, Chapelot D, Fantino M, et al. (2002) Snacks consumed in a nonhungry state have poor satiating efficiency: influence of snack composition on substrate utilization and hunger. Am J Clin Nutr 76, 518-528.

16. Raben A, Agerholm-Larsen L, Flint A, et al. (2003) Meals with similar energy densities but rich in protein, fat, carbohydrate, or alcohol have different effects on energy expenditure and substrate metabolism but not on appetite and energy intake. Am J Clin Nutr 77, 91-100.

17. Reid M \& Hetherington M (1997) Relative effects of carbohydrates and protein on satiety - a review of methodology. Neurosci Biobehav Rev 21, 295-308.

18. Mattes RD (2006) Fluid energy - where's the problem? J Am Diet Assoc 106, 1956-1961.

19. Leidy HJ, Bales-Voelker LI \& Harris CT (2011) A protein-rich beverage consumed as a breakfast meal leads to weaker appetitive and dietary responses $v$. a protein-rich solid breakfast meal in adolescents. Br J Nutr 106, 37-41.

20. Martens MJ, Lemmens SG, Born JM, et al. (2011) A solid high-protein meal evokes stronger hunger suppression than a liquefied high-protein meal. Obesity (Silver Spring) 19, 522-527.

21. Akhavan T, Luhovyy BL \& Anderson GH (2011) Effect of drinking compared with eating sugars or whey protein on short-term appetite and food intake. Int J Obes (Lond) 35 , 562-569.

22. Potier M, Fromentin G, Lesdema A, et al. (2010) The satiety effect of disguised liquid preloads administered acutely and differing only in their nutrient content tended to be weaker for lipids but did not differ between proteins and carbohydrates in human subjects. BrJ Nutr 104, 1406-1414.

23. Fromentin G, Feurte S \& Nicolaidis S (1998) Spatial cues are relevant for learned preference/aversion shifts due to amino-acid deficiencies. Appetite 30, 223-234.
24. Booth DA, Lee M \& McAleavey C (1976) Acquired sensory control of satiation in man. Br J Psychol 67, 137-147.

25. Louis-Sylvestre J, Tournier A, Verger P, et al. (1989) Learned caloric adjustment of human intake. Appetite 12, 95-103.

26. Yeomans MR, Weinberg L \& James S (2005) Effects of palatability and learned satiety on energy density influences on breakfast intake in humans. Physiol Behav 86, 487-499.

27. Faipoux R, Tome D, Bensaid A, et al. (2006) Yeast proteins enhance satiety in rats. $J$ Nutr 136, 2350-2356.

28. Anderson GH, Tecimer SN, Shah D, et al. (2004) Protein source, quantity, and time of consumption determine the effect of proteins on short-term food intake in young men. J Nutr 134, 3011-3015.

29. Veldhorst MA, Nieuwenhuizen AG, Hochstenbach-Waelen A, et al. (2009) A breakfast with $\alpha$-lactalbumin, gelatin, or gelatin + TRP lowers energy intake at lunch compared with a breakfast with casein, soy, whey, or whey-GMP. Clin Nutr 28, 147-155.

30. Lang V, Bellisle F, Alamowitch C, et al. (1999) Varying the protein source in mixed meal modifies glucose, insulin and glucagon kinetics in healthy men, has weak effects on subjective satiety and fails to affect food intake. Eur J Clin Nutr 53, 959-965.

31. Lang V, Bellisle F, Oppert JM, et al. (1998) Satiating effect of proteins in healthy subjects: a comparison of egg albumin, casein, gelatin, soy protein, pea protein, and wheat gluten. Am J Clin Nutr 67, 1197-1204.

32. Fromentin G, Feurte S, Nicolaidis S, et al. (2000) Parabrachial lesions disrupt responses of rats to amino acid devoid diets, to protein-free diets, but not to high-protein diets. Physiol Behav 70, 381-389.

33. Gietzen DW, Hao S \& Anthony TG (2007) Mechanisms of food intake repression in indispensable amino acid deficiency. Annu Rev Nutr 27, 63-78.

34. Harper AE \& Peters JC (1989) Protein intake, brain amino acid and serotonin concentrations and protein self-selection. J Nutr 119, 677-689.

35. Tews JK, Repa JJ \& Harper AE (1992) Protein selection by rats adapted to high or moderately low levels of dietary protein. Physiol Behav 51, 699-712.

36. Bensaid A, Tome D, L'Heureux-Bourdon D, et al. (2003) A high-protein diet enhances satiety without conditioned taste aversion in the rat. Physiol Behav 78, 311-320.

37. L'Heureux-Bouron D, Tome D, Bensaid A, et al. (2004) A very high $70 \%$-protein diet does not induce conditioned taste aversion in rats. J Nutr 134, 1512-1515.

38. Kinzig KP, Hargrave SL, Hyun J, et al. (2007) Energy balance and hypothalamic effects of a high-protein/low-carbohydrate diet. Physiol Behav 92, 454-460.

39. Ropelle ER, Pauli JR, Fernandes MF, et al. (2008) A central role for neuronal AMP-activated protein kinase (AMPK) and mammalian target of rapamycin (mTOR) in high-protein diet-induced weight loss. Diabetes 57, 594-605.

40. Pichon L, Potier M, Tome D, et al. (2008) High-protein diets containing different milk protein fractions differently influence energy intake and adiposity in the rat. BrJ Nutr 99, 739-748.

41. Pichon L (2008) Rôles de la composition en macronutriments et de la nature protéique du régime dans le comportement alimentaire et le métabolisme protéino-énergétique chez le rat (Roles of macronutrient composition and protein nature of the regime in feeding behavior and proteinenergy metabolism in rats). Thesis Abies. Paris: Agroparistech.

42. Kondoh T, Mallick HN \& Torii K (2009) Activation of the gut-brain axis by dietary glutamate and physiologic 
significance in energy homeostasis. Am J Clin Nutr 90, 832S-837S.

43. Boutry C, Bos C, Matsumoto H, et al. (2011) Effects of monosodium glutamate supplementation on glutamine metabolism in adult rats. Front Biosci (Elite Ed) 3, 279-290.

44. Harper AE, Benevenga NJ \& Wohlhueter RM (1970) Effects of ingestion of disproportionate amounts of amino acids. Physiol Rev 50, 428-558.

45. McArthur LH, Kelly WF, Gietzen DW, et al. (1993) The role of palatability in the food intake response of rats fed high-protein diets. Appetite 20, 181-196.

46. L'Heureux-Bouron D, Tome D, Bensaid A, et al. (2004) Preabsorptive factors are not the main determinants of intake depression induced by a high-protein diet in the rat. Physiol Behav 81, 499-504.

47. Ashley JM, St Jeor ST, Perumean-Chaney S, et al. (2001) Meal replacements in weight intervention. Obes Res 9 , Suppl. 4, 312S-320S.

48. Noakes M, Foster PR, Keogh JB, et al. (2004) Meal replacements are as effective as structured weight-loss diets for treating obesity in adults with features of metabolic syndrome. J Nutr 134, 1894-1899.

49. Sacks FM, Bray GA, Carey VJ, et al. (2009) Comparison of weight-loss diets with different compositions of fat, protein, and carbohydrates. $N$ Engl J Med 360, 859-873.

50. Gilbert JA, Bendsen NT, Tremblay A, et al. (2011) Effect of proteins from different sources on body composition. Nutr Metab Cardiovasc Dis 21, Suppl. 2, B16-B31.

51. Treyzon L, Chen S, Hong K, et al. (2008) A controlled trial of protein enrichment of meal replacements for weight reduction with retention of lean body mass. Nutr J 7,23 .

52. Layman DK, Evans EM, Erickson D, et al. (2009) A moderate-protein diet produces sustained weight loss and longterm changes in body composition and blood lipids in obese adults. J Nutr 139, 514-521.

53. Chaston TB, Dixon JB \& O'Brien PE (2007) Changes in fat-free mass during significant weight loss: a systematic review. Int J Obes (Lond) 31, 743-750.

54. Weigle DS, Breen PA, Matthys CC, et al. (2005) A highprotein diet induces sustained reductions in appetite, ad libitum caloric intake, and body weight despite compensatory changes in diurnal plasma leptin and ghrelin concentrations. Am J Clin Nutr 82, 41-48.

55. Beauchamp GK (2009) Sensory and receptor responses to umami: an overview of pioneering work. Am J Clin Nutr 90, 723S-727S.

56. Powley TL \& Phillips RJ (2004) Gastric satiation is volumetric, intestinal satiation is nutritive. Physiol Behav 82, 69-74.

57. Ma J, Stevens JE, Cukier K, et al. (2009) Effects of a protein preload on gastric emptying, glycemia, and gut hormones after a carbohydrate meal in diet-controlled type 2 diabetes. Diabetes Care 32, 1600-1602.

58. Janssen $\mathrm{P}$, Vanden Berghe $\mathrm{P}$, Verschueren $\mathrm{S}$, et al. (2011) Review Article: the role of gastric motility in the control of food intake. Aliment Pharmacol Ther 33, 880-894.

59. Raybould HE, Glatzle J, Freeman SL, et al. (2006) Detection of macronutrients in the intestinal wall. Auton Neurosci 125, 28-33.

60. Lindemann B (2001) Receptors and transduction in taste. Nature 413, 219-225.

61. Liou AP, Chavez DI, Espero E, et al. (2011) Protein hydrolysate-induced cholecystokinin secretion from enteroendocrine cells is indirectly mediated by the intestinal oligopeptide transporter PepT1. Am J Physiol Gastrointest Liver Physiol 300, G895-G902.
62. Darcel NP, Liou AP, Tome D, et al. (2005) Activation of vagal afferents in the rat duodenum by protein digests requires PepT1. J Nutr 135, 1491-1495.

63. Conigrave AD, Quinn SJ \& Brown EM (2000) L-Amino acid sensing by the extracellular $\mathrm{Ca}^{2+}$-sensing receptor. Proc Natl Acad Sci U S A 97, 4814-4819.

64. Raybould HE (1991) Capsaicin-sensitive vagal afferents and CCK in inhibition of gastric motor function induced by intestinal nutrients. Peptides 12, 1279-1283.

65. Maljaars PW, Peters HP, Mela DJ, et al. (2008) Ileal brake: a sensible food target for appetite control. A review. Physiol Behav 95, 271-281.

66. Meyer JH, Hlinka M, Tabrizi Y, et al. (1998) Chemical specificities and intestinal distributions of nutrient-driven satiety. Am J Physiol 275, R1293-R1307.

67. Moran TH \& Dailey MJ (2011) Intestinal feedback signaling and satiety. Physiol Behav 105, 77-81.

68. Batterham RL, Heffron H, Kapoor S, et al. (2006) Critical role for peptide $\mathrm{YY}$ in protein-mediated satiation and body-weight regulation. Cell Metab 4, 223-233.

69. Karhunen LJ, Juvonen KR, Huotari A, et al. (2008) Effect of protein, fat, carbohydrate and fibre on gastrointestinal peptide release in humans. Regul Pept 149, 70-78.

70. Blom WA, Lluch A, Stafleu A, et al. (2006) Effect of a highprotein breakfast on the postprandial ghrelin response. Am J Clin Nutr 83, 211-220.

71. Bowen J, Noakes M \& Clifton PM (2006) Appetite regulatory hormone responses to various dietary proteins differ by body mass index status despite similar reductions in ad libitum energy intake. J Clin Endocrinol Metab 91, 2913-2919.

72. Veldhorst M, Smeets A, Soenen S, et al. (2008) Proteininduced satiety: effects and mechanisms of different proteins. Physiol Behav 94, 300-307.

73. Smeets AJ, Soenen S, Luscombe-Marsh ND, et al. (2008) Energy expenditure, satiety, and plasma ghrelin, glucagon-like peptide 1 , and peptide tyrosine-tyrosine concentrations following a single high-protein lunch. J Nutr $\mathbf{1 3 8}$, 698-702.

74. Hall WL, Millward DJ, Long SJ, et al. (2003) Casein and whey exert different effects on plasma amino acid profiles, gastrointestinal hormone secretion and appetite. Br J Nutr 89, 239-248.

75. de Lartigue G, Lur G, Dimaline R, et al. (2010) EGR1 is a target for cooperative interactions between cholecystokinin and leptin, and inhibition by ghrelin, in vagal afferent neurons. Endocrinology 151, 3589-3599.

76. Rehfeld JF (2011) Incretin physiology beyond glucagon-like peptide 1 and glucose-dependent insulinotropic polypeptide: cholecystokinin and gastrin peptides. Acta Physiol (Oxf) 201, 405-411.

77. Penhoat A, Mutel E, Correig MA, et al. (2011) Proteininduced satiety is abolished in the absence of intestinal gluconeogenesis. Physiol Behav 105, 89-93.

78. Berthoud HR, Shin AC \& Zheng H (2011) Obesity surgery and gut-brain communication. Physiol Behav 105, 106-119.

79. L'Heureux-Bouron D, Tome D, Rampin O, et al. (2003) Total subdiaphragmatic vagotomy does not suppress high protein diet-induced food intake depression in rats. $J$ Nutr 133, 2639-2642.

80. Brenner L, Yox DP \& Ritter RC (1993) Suppression of sham feeding by intraintestinal nutrients is not correlated with plasma cholecystokinin elevation. Am J Physiol 264, R972-R976.

81. Stepien M, Gaudichon C, Azzout-Marniche D, et al. (2010) Postprandial nutrient partitioning but not energy 
expenditure is modified in growing rats during adaptation to a high-protein diet. J Nutr 140, 939-945.

82. Veldhorst MA, Westerterp-Plantenga MS \& Westerterp KR (2009) Gluconeogenesis and energy expenditure after a high-protein, carbohydrate-free diet. Am J Clin Nutr 90, 519-526.

83. Nuttall FQ, Ngo A \& Gannon MC (2008) Regulation of hepatic glucose production and the role of gluconeogenesis in humans: is the rate of gluconeogenesis constant? Diabetes Metab Res Rev 24, 438-458.

84. Veldhorst MA, Westerterp KR \& Westerterp-Plantenga MS (2012) Gluconeogenesis and protein-induced satiety. $B r$ J Nutr 107, 595-600.

85. Choi YH, Fletcher PJ \& Anderson GH (2001) Extracellular amino acid profiles in the paraventricular nucleus of the rat hypothalamus are influenced by diet composition. Brain Res 892, 320-328.

86. Boirie Y, Dangin M, Gachon P, et al. (1997) Slow and fast dietary proteins differently modulate postprandial protein accretion. Proc Natl Acad Sci U S A 94, 14930-14935.

87. Mellinkoff SM, Frankland M, Boyle D, et al. (1956) Relationship between serum amino acid concentration and fluctuations in appetite. $J$ Appl Physiol 8, 535-538.

88. Blundell JE \& Latham CJ (1979) Serotonergic influences on food intake: effect of 5-hydroxytryptophan on parameters of feeding behaviour in deprived and free-feeding rats. Pharmacol Biochem Behav 11, 431-437.

89. Nieuwenhuizen AG, Hochstenbach-Waelen A, Veldhorst MA, et al. (2009) Acute effects of breakfasts containing $\alpha$-lactalbumin, or gelatin with or without added tryptophan, on hunger, 'satiety' hormones and amino acid profiles. Br J Nutr 101, 1859-1866.

90. Bassil MS, Hwalla N \& Obeid OA (2007) Meal pattern of male rats maintained on histidine-, leucine-, or tyrosinesupplemented diet. Obesity (Silver Spring) 15, 616-623.

91. Kondoh T, Tsurugizawa T \& Torii K (2009) Brain functional changes in rats administered with monosodium l-glutamate in the stomach. Ann N Y Acad Sci 1170, 77-81.

92. Kasaoka S, Tsuboyama-Kasaoka N, Kawahara Y, et al. (2004) Histidine supplementation suppresses food intake and fat accumulation in rats. Nutrition 20, 991-996.

93. Mercer LP (1997) Histamine and the neuroregulation of food intake. Nutrition 13, 581-582.

94. Berthoud HR (2002) Multiple neural systems controlling food intake and body weight. Neurosci Biobehav Rev 26, 393-428.

95. Darcel N, Fromentin G, Raybould HE, et al. (2005) Fos-positive neurons are increased in the nucleus of the solitary tract and decreased in the ventromedial hypothalamus and amygdala by a high-protein diet in rats. J Nutr 135, 1486-1490.

96. Phifer CB \& Berthoud HR (1998) Duodenal nutrient infusions differentially affect sham feeding and Fos expression in rat brain stem. Am J Physiol 274, R1725-R1733.

97. Faipoux R, Tome D, Gougis S, et al. (2008) Proteins activate satiety-related neuronal pathways in the brainstem and hypothalamus of rats. $J$ Nutr $\mathbf{1 3 8}, 1172-1178$.

98. Cowley MA, Smart JL, Rubinstein M, et al. (2001) Leptin activates anorexigenic POMC neurons through a neural network in the arcuate nucleus. Nature 411, 480-484.

99. Pillot B, Duraffourd C, Begeot M, et al. (2011) Role of hypothalamic melanocortin system in adaptation of food intake to food protein increase in mice. PLoS One 6, e19107.

100. Cota D, Proulx K, Smith KA, et al. (2006) Hypothalamic mTOR signaling regulates food intake. Science 312, 927-930.

101. Morrison CD, Xi X, White CL, et al. (2007) Amino acids inhibit Agrp gene expression via an mTOR-dependent mechanism. Am J Physiol Endocrinol Metab 293, E165-E171.

102. Kelley AE (2004) Ventral striatal control of appetitive motivation: role in ingestive behavior and reward-related learning. Neurosci Biobehav Rev 27, 765-776.

103. Faipoux R (2007) Caractérisation de l'effet satiétogène des protéines et mécanismes centraux impliqués; cas particulier des protéines de levures (Characterising the satiety effect of proteins and central mechanisms involved; particular case of yeast proteins). Thesis Abies. Paris Agroparistech.

104. Kirouac GJ \& Ganguly PK (1995) Topographical organization in the nucleus accumbens of afferents from the basolateral amygdala and efferents to the lateral hypothalamus. Neuroscience 67, 625-630.

105. Stratford TR \& Kelley AE (1999) Evidence of a functional relationship between the nucleus accumbens shell and lateral hypothalamus subserving the control of feeding behavior. J Neurosci 19, 11040-11048.

106. Zheng H, Corkern M, Stoyanova I, et al. (2003) Peptides that regulate food intake: appetite-inducing accumbens manipulation activates hypothalamic orexin neurons and inhibits POMC neurons. Am J Physiol Regul Integr Comp Physiol 284, R1436-R1444.

107. Chaumontet C, Darcel N, Tomé D, et al. (2011) Postprandial activation of accumbens nucleus, brain area involved in hedonism, is decreased by high protein diet. FASEB J 25, 328.1 .

108. Anderson GH \& Moore SE (2004) Dietary proteins in the regulation of food intake and body weight in humans. J Nutr 134, 974S-979S. 